\title{
ETNOZOLOOGI UNTUK RITUAL ADAT MASYARAKAT DAYAK KAYAAN DI DESA PADUA MENDALAM KECAMATAN PUTUSSIBAU UTARA KABUPATEN KAPUAS HULU
}

\author{
(Ethnozoology For Traditional Rituals Dayak Kayaan Community In Padua Mendalam Viillage \\ Putussibau Utara District, Kapuas Hulu Regency)
}

\author{
Marcelius Mering, M. Sofwan Anwari, Hafiz Ardian \\ Fakultas Kehutanan Universitas Tanjung Pura Jl. Daya Nasional Pontianak 78124 \\ Email: marcelmarcel776@gmail.com
}

\begin{abstract}
The local People of Kalimantan until now still depend on nature, they uilize flora and fauna for daily needs. Dayak Kayaan community in Padua Mendalam Village, Putussibau Utara District, Kapuas Hulu Regency have diversity in the utilization of animal Species including the use of animals for traditional rituals. The purpose of this study was to collect data of animals species that used for traditional rituals Dayak Kayaan people in Padua Mendalam Village, Putussibau Utara District, Kapuas Hulu District. Data collection with survey method and interviews with selected respondents using snowball sampling technique. The results there were 9 species from 9 families, every species of family consisted of only 1 species. The body parts used for traditional rituals are blood, the whole body, tail, head, feathers an shells. How to use every part of the body has a difference depending on the type of traditional rituals performed.
\end{abstract}

Keyword: Ethnozoology For Traditional Rituals Community Dayak Kayaan.

\section{PENDAHULUAN}

Pulau Kalimantan merupakan sebuah pulau di Indonesia yang memiliki banyak keunikan dan daya tarik termasuk juga kaya dengan warisan budaya. Pulau Kalimantan terkenal dengan hutan tropis serta memiliki sumber daya alam yang terbanyak di Indonesia. Flora dan fauna eksotis juga ditawarkan oleh bumi Kalimantan. Pulau ini pada awalnya, dihuni oleh orang-orang Dayak sebagai suku asli Kalimantan. Biasanya mereka tinggal di dalam hutan dan hidup secara nomaden. Perubahan dan arus modernisasi saat ini telah membawa beberapa masyarakat asli Suku Dayak untuk bergaul dengan berbaur menjadi satu dengan masyarakat dari berbagai suku di perkotaan. Masyarakat Suku Dayak juga merupakan sub etnis Austronesia yang dianggap sebagai penduduk asli yang mendiami Pulau Kalimantan yang terkenal dengan keanekaragaman hayati yang tinggi dan sebagai pulau terbesar ke 3 di dunia yang telah diakui secara internasional (Noerwid 2010).

Masyarakat pedalaman kalimantan yang hidup di dalam maupun di sekitar hutan masih menggantungkan hidupnya pada hutan yang ada di sekitar mereka. Keragaman dalam pemanfaatan satwa mendorong terbentuknya pola yaitu sebuah sistem atau cara kerja yang tetap dalam memanfaatkan berbagai jenis 
satwa, sebagai contoh di Desa Seragen, Denpasar, Bali penyu dimanfaatkan sebagai upacara agama Hindu (Kartikasari 2008). Hal ini berkaitan erat dengan proses interaksi yang berkembang antara etnis tertentu yang tinggal di sekitar hutan dengan alam lingkungannya dari waktu ke waktu ( $\mathrm{Li}$ 1999). Interaksi yang kuat tersebut melahirkan cara tersendiri pada komunitas masyarakat dalam memperlakukan sumberdaya alamnya. Keanekaragaman dan endemisitas fauna di Kalimantan merupakan kekayaan biodiversitas yang harus tetap dijaga. Terdapat 29 jenis satwa yang diyakini masyarakat sekitar Taman Betung Kerihun sebagai pengobatan (Putra 2008). Menurut Suparlan (2005) dalam kehidupan, manusia tidak lepas dari pemanfaatan berbagai sumber daya hayati. Sumber daya hayati yang dimaksud yaitu tumbuh-tumbuhan dan hewan.

Pemanfaatan hewan untuk ritual adat adalah pemanfaatan hewan yang dipercayai untuk ritual adat seperti ritual sebelum pernikahan maupun saat upacara pernikahan biasanya hewan yang digunakan adalah babi tetapi babi hanya dimanfaatkan untuk konsumsi. Hewan untuk ritual adat biasanya digunakan untuk pemanggilan makhluk gaib. Pemanfaatan hewan untuk mistis biasanya lebih dikenal dengan hewan yang dapat digunakan dalam kepercayaan masyarakat sekitar biasanya hewan yang dapat memberi pertanda buruk dan pertanda baik. Hewan yang dimanfaatkan untuk pengobatan biasanya hewan yang sering dijumpai masyarakat sekitar seperti kelelawar, cacing, ikan gabus dan lainnya.

Salah satu etnis asli yang terdapat pada Provinsi Kalimantan Barat yaitu Dayak Kayaan di Desa Padua Mendalam Kecamatan Putusibau Utara, Kabupaten Kapuas Hulu. Masyarakat Dayak Kayaan ini juga memiliki keragaman dalam pemanfaatan fauna baik untuk bahan pangan, obat-obatan, upacara adat dan supranatural. Masyarakat Dayak Kayaan yang hidup secara berkelompok telah diketahui memanfaatkan berbagai jenis keanekaragaman hayati untuk kebutuhan hidup. Hubungan antara manusia dengan alam membentuk nilainilai yang arif dan menyatu dalam mengelola alam lingkungan. Informasi dan pengetahuan mengenai pemanfaatan fauna oleh Suku Dayak Kayaan untuk ritual adat, mistis dan pengobatan masih belum diketahui, oleh karena itu diperlukan penelitian mengenai etnozoologi pada Suku Dayak Kayaan di Desa Padua Mendalam Kecamatan Putussibau Utara, Kabupaten Kapuas Hulu. Tujuan penelitian ini untuk mendata jenis hewan dan bagian yang dimanfaatkan untuk ritual adat masyarakat Dayak Kayaan di Desa Padua Mendalam Kecamatan Putussibau Utara Kabupaten Kapuas Hulu.

\section{METODE PENELITIAN}

Pengumpulan data dilakukan dengan metode survei dan wawancara serta pengamatan langsung di lapangan. 
Wawancara ditunjukan kepada kepala desa, kepala adat, dukun, pemburu, orang tua, ibu-ibu, serta masyarakat yang dianggap mengetahui dan memiliki pengetahuan mengenai pemanfaatan jenis hewan.

Pengumpulan data di Desa Padua Mendalam Kecamatan Putussibau Utara Kabupaten Kapuas Hulu, ini dilakukan dengan melakukan wawancara mendalam terhadap responden yang terpilih dengan menggunakan metode survei. Pemilihan responden ini dilakukan dengan menggunakan teknik snowball sampling yaitu dengan menentukan responden kunci untuk kemudian menentukan responden lainnya berdasarkan informasi dari responden sebelumnya, demikian juga untuk seterusnya (Poerwandi 1998). Responden kunci adalah orang yang memiliki pengetahuan luas mengenai jenis hewan, cara mendapatkannya, bagian yang digunakan, cara memanfaatkannya serta kegunaannya.
Wawancara yang telah dilakukan, keterangannya harus dilakukan pencatatan yang lengkap mengenai keterangan jenis-jenis hewan yang dimanfaatkan oleh masyarakat setempat.

Analisa data yang digunakan adalah metode deskriftif kualitatif, yaitu mendeskripsikan data yang dikumpulkan berupa kata-kata, gambar dan bukan angka. Data yang berasal dari wawancara, catatan lapangan, jenis hewan yang dimanfaatkan, cara mendapatkan dan memanfaatkannya serta kegunaannya.

\section{HASIL DAN PEMBAHASAN}

Berdasarkan hasil wawancara yang dilakukan terhadap responden terpilih, diperoleh 9 jenis hewan dari 9 famili yang dimanfaatkan oleh masyarakat di Desa Padua Mendalam Kecamatan Putussibau Utara Kabupaten Kapuas Hulu untuk ritual adat. Jenis-jenis hewan yang dimanfaatkan untuk ritual adat tersebut dapat dilihat pada tabel 1 . 
Tabel 1. Pemanfaatan hewan untuk ritual adat oleh masyarakat Suku Dayak Kayaan di Desa Padua Mendalam Kecamatan Putussibau Utara Kabupaten Kapuas Hulu.(Utilization Of Animals For Traditional Rituals By Dayak Kayaan Community In Padua Mendalam Viillage, Putussibau Utara District, Kapuas Hulu Regency).

\begin{tabular}{|c|c|c|c|c|c|}
\hline No & $\begin{array}{l}\text { Nama } \\
\text { Lokal }\end{array}$ & $\begin{array}{l}\text { Nama } \\
\text { Indonesia }\end{array}$ & Nama Ilmiah & $\begin{array}{l}\text { Bagian yang } \\
\text { dimanfaatkan }\end{array}$ & $\begin{array}{l}\text { Makna dan } \\
\text { Ritual Adat }\end{array}$ \\
\hline 1 & Uting & Babi & Sus scrofa & $\begin{array}{l}\text { Darah dan } \\
\text { Seluruh tubuh }\end{array}$ & $\begin{array}{l}\text { Mela, } \\
\text { Penangkal Roh } \\
\text { jahat, simbol } \\
\text { kekeluargaan }\end{array}$ \\
\hline 2 & $\begin{array}{l}\text { Asok } \\
\text { pitam }\end{array}$ & Anjing hitam & $\begin{array}{l}\text { Canis lupus } \\
\text { familiaris }\end{array}$ & Seluruh tubuh & $\begin{array}{l}\text { Pemecahan } \\
\text { perkara }\end{array}$ \\
\hline 3 & $\begin{array}{l}\text { Seluang } \\
\text { Guhun }\end{array}$ & Seluang Batang & Rasbora sp & $\begin{array}{l}\text { Kepala dan } \\
\text { ekor }\end{array}$ & $\begin{array}{l}\text { Sebagai } \\
\text { perlindungan dari } \\
\text { hal jahat untuk } \\
\text { pasangan suami } \\
\text { istri, Pernikahan }\end{array}$ \\
\hline 4 & $\begin{array}{l}\text { Henyaap } \\
\text { Kapong }\end{array}$ & $\begin{array}{l}\text { Ayam } \\
\text { Kampung }\end{array}$ & $\begin{array}{l}\text { Gallus gallus } \\
\text { domesticus }\end{array}$ & Seluruh tubuh & $\begin{array}{l}\text { Memberi Sesaji } \\
\text { untuk mahluk } \\
\text { halus, Perubahan } \\
\text { Nama Orang }\end{array}$ \\
\hline 5 & Sii & Susuh Kura & $\begin{array}{l}\text { Sulcospira } \\
\text { testudinaria }\end{array}$ & Cangkang & $\begin{array}{l}\text { Penangkal roh } \\
\text { yang meninnggal } \\
\text { Dunia }\end{array}$ \\
\hline 6 & $\begin{array}{l}\text { Manuk } \\
\text { Tingaang }\end{array}$ & $\begin{array}{l}\text { Burung } \\
\text { Enggang }\end{array}$ & $\begin{array}{l}\text { Buceros } \\
\text { rhinoceros }\end{array}$ & $\begin{array}{l}\text { Kepala dan } \\
\text { Bulu }\end{array}$ & $\begin{array}{l}\text { Mensyukuri hasil } \\
\text { panen padi } \\
\text { (Dange) }\end{array}$ \\
\hline 7 & $\begin{array}{l}\text { Manuk } \\
\text { Bukang }\end{array}$ & Ketupung & $\begin{array}{l}\text { Sasia } \\
\text { abnormis }\end{array}$ & Seluruh Tubuh & $\begin{array}{l}\text { Agar mendapatkan } \\
\text { hasil padi yang } \\
\text { melimpah }\end{array}$ \\
\hline 8 & $\begin{array}{l}\text { Manuk } \\
\text { Hisit }\end{array}$ & $\begin{array}{l}\text { Burung madu } \\
\text { kelapa }\end{array}$ & $\begin{array}{l}\text { Anthreptes } \\
\text { malacensis }\end{array}$ & Seluruh tubuh & $\begin{array}{l}\text { Meminta } \\
\text { perlindungan dan } \\
\text { kesehatan untuk } \\
\text { padi }\end{array}$ \\
\hline 9 & $\begin{array}{l}\text { Manuk } \\
\text { Telajaan }\end{array}$ & $\begin{array}{l}\text { Burung Cililin } \\
\text { Coklat }\end{array}$ & $\begin{array}{l}\text { Platylophus } \\
\text { galericulatus }\end{array}$ & Seluruh tubuh & $\begin{array}{l}\text { Hidup tenang } \\
\text { dibumi, dan hasil } \\
\text { padi berlimpah }\end{array}$ \\
\hline
\end{tabular}

a. Uting atau Babi merupakan hewan yang dimanfaatkan oleh masyarakat Desa Padua Mendalam, hampir seluruh tubuh hewan tersebut digunakan untuk ritual adat mulai dari hukum adat, gawai dayak (Dange) dan ritual lainnya. Masyarakat Suku Dayak Kayaan percaya terhadap babi sebagai hewan yang dianggap dapat menghilangkan beban dalam kehidupan, ritual tersebut dilakukan saat gawai Dayak
(Dange) atau setelah panen padi dan nama ritual tersebut adalah Mela, selanjutnya babi tersebut dibersihkan dan dipotong kecil bersama makanan tradisisonal yang disebut Pitoh, lalu dibagikan ke setiap rumah. Tujuan ritual adat yang menggunakan babi yaitu untuk mengucap syukur kepada Tuhan, dan mengumpulkan keluarga besar Suku Dayak kayaan di Desa Padua Mendalam Kecamatan 
Putussibau Utara Kabupaten Kapuas Hulu. Selain masyarakat Dayak Kayaan Desa Padua Mendalam di daerah lain seperti masyarakat Dayak Kanayant Desa Babane Kalimantan Barat babi juga digunakan sebagai symbol ikatan antar keluarga dan penangkal roh jahat (Pilatus 2017). Babi berdasarkan pendapat umum menyatakan bahwa bangsa babi merupakan hewan yang paling awal dijinakan, bukan kucing ataupun anjing. Hal ini terbukti dengan adanya penemuaan lukisan dan ukiran babi yang berumur lebih dari 25.000 tahun yang lalu (Agung 1993).

b. Asok atau Anjing juga merupakan hewan yang digunakan masyarakat Suku Dayak Kayaan Mendalam dalam melakukan ritual adat yang disebut Pelemala, bagian tubuh yang digunakan adalah seluruh tubuh hewan. Ritual adat biasanya dilakukan jika dua belah pihak mendapatkan perkara misalnya perkara batas tanah, jika perkara tersebut tidak dapat diselesaikan secara kekeluargaan maka harus diselesaikan secara Pelemala dan hewan yang digunakan adalah anjing, dengan tujuan agar perkara yang terjadi antara dua belah pihak tersebut dapat diselesaikan secara adil.

c. Seluaang Guhun atau Seluang Batang adalah hewan yang hidup dirawa atau perairan air tawar dengan ukuran tubuh yang kecil. Seluang Batang juga merupakan hewan yang dimanfaatkan oleh masyarakat Suku Dayak Kayaan Mendalam sebagai hewan untuk ritual adat misalnya pernikahan adat, bagian yang digunakan adalah kepala dan ekor. Bagian kepala dibagikan kepada pria dikarenakan pria tersebut sebagai kepala keluarga dan bagian ekor di bagikan kepada wanita yang dianggap sebagai ibu rumah tangga. Masyarakat Dayak Kayaan Mendalam percaya bahwa hewan tersebut sebagai simbol ikatan kekeluargaan, dan bertujuan untuk mendapatkan kehidupan yang baik dan jauh dari segala yang jahat.

d. Henyaap Kapong atau Ayam kampung merupakan hewan yang dipercya oleh masyarakat Dayak Kayaan Mendalam sebagai hewan yang digunakan untuk ritual adat terutama untuk perubahan nama seseorang atau nama marga. Hewan tersebut diberikan kepada mahluk halus, dengan tujuan nama yang digunakan tersebut dapat memberikan kekuatan dalam menjalani kehidupan sebagai orang Dayak Kayaan Mendalam dan jauh dari segala yang jahat. Ayam kampung berperan penting dalam upacara adat serta pesta-pesta besar seperti upacara pernikahan adat dan berdukun (Eprilurahman $d k k$ 2012).

e. Sii atau Susuh Kura adalah hewan yang hidup di perairan air tawar, terutama di sungai mendalam ( Hungee medalaam) hingga saat ini hewan tersebut masih mudah ditemukan dan dimanfaatkan. Masyarakat Suku Dayak Kayaan di Desa Padua Mendalam hingga saat ini masih memanfaatkan hewan tersebut sebagai hewan untuk ritual adat, ritual tersebut dilakukan saat ada keluarga yang meninggal dunia, bagian tubuh yang digunakan adalah seluruh tubuh. Masyarakat Dayak Kayaan di Desa Padua Mendalam memanfaatkan hewan tersebut dengan tujuan dapat menangkal roh yang telah meninggal, terutama untuk anakanak dalam keluarga yang ditinggalkan.

f. Manuk Hisit atau Burung Madu Kelapa juga merupakan hewan yang dimanfaatkan oleh Suku Dayak Kayaan di Desa Padua Mendalam untuk ritual adat misalnya berdoa kepada Hsit untuk hidup yang baik dan hasil ladang yang melimpah. Hasil wawancara di Desa Padua Mendalam bersama salah satu narasumber mengatakan bahwa upacara ritual adat tersebut saat ini masih dilakukan dengan harapan Manuk Hisit tersebut memberikan 
kehidupan yang baik di bumi dan hasil ladang yang berlimpah, masyarakat Suku Dayak Kayaan Mendalam memiliki cara unik dalam ritual adat tersebut, dengan mencari suara dari burung dan menghidupkan api di bawah suara tersebut, setalah apinya padam mereka menancapkan kayu atau ranting di bekas api tersebut dan ke esokan harinya mereka baru mulai berkerja di lahan yang telah dilakukan ritual dengan tujuan agar lahan yang digunakan dapat memberikan hasil panen yang berlimpah. Proses ritual adat terdapat empat orang yang dipercaya mengetahui cara melakukan ritual tersebut.

g. Manuk Tingaang atau Burung Enggang adalah salah satu hewan yang sangat mulia bagi masyarakat Suku Dayak Kayaan Mendalam sejak dulu, hingga saat ini hewan tersebut masih di manfaatkan. Menurut hasil wawancara terhadap salah satu responden mengatakan bahwa hewan ini digunakan dalam ritual adat mulai dari Mela, Ngiaan dan lainnya yang bertujuan untuk mendapatkan perlindungan.
Masyarakat Suku Dayak Kayaan Mendalam juga menilai bahwa Tingaang atau Enggang merupakan simbol kebesaran dan kemuliaan.

Mela merupakan ritual adat yang dilakukan masyarakat Suku Dayak Kayaan Mendalam di hari besar yaitu saat syukuran panen padi (Dange) di dalam pondok yang telah disediakan, pondok tersebut dibangun oleh masyarakat tepat di sebelah rumah Betang (Umaa Aruu) dengan ukuran sedang dan ritual tersebut di pimpin oleh satu orang tua yang dipercaya mengetahui cara dari ritual adat tersebut. Hewan yang digunakan adalah Tingaang atau burung Enggang bagian yang dimanfaatkan adalah kepala, paruh dan bulu, sedangkan Ngiaan merupakan ritual adat yang dilaksanakan setelah proses ritual mela. Ritual adat ini dilakukan oleh masyarakat Dayak Kayaan Mendalam dengan tujuan dapat memberikan keberkahan dalam kehidupan dan kegiatan berladang.

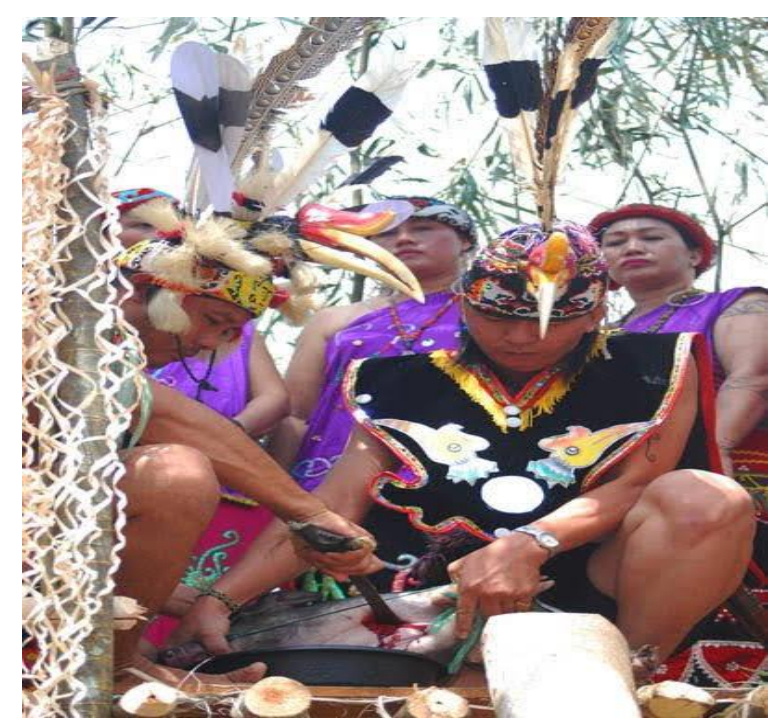

Gambar 1. Ritual Adat Mela di Desa Padua Mendalam, Kecamatan Putussibau Utara, Kabupaten Kapuas Hulu.(Traditional Rituals Mela Dayak Kayaan Community In Padua Mendalam Village, Putussibau Utara District, Kapuas Hulu Regency).

h. Manuk Bukang atau Burung Ketupung juga merupakan hewan yang sangat dipercaya masyarakat Suku Dayak Kayaan

Mendalam dalam nilai ritual adat, dengan 
demikian hewan tersebut hingga saat ini masih dimanfaatkan. Bagian tubuh yang digunakan yaitu seluruh tubuh hewan, proses ritual adat tersebut dilakukan oleh empat orang yang dipercaya mengetahui cara dalam melakukan ritual adat tersebut. Ritual adat ini bertujuan untuk mendapat perlindungan, keberkahan dan ketenangan dalam kehidupan masyarakat Dayak Kayaan Mendalam.

i. Manuk telajaan atau Burung Cililin coklat merupakan hewan yang dipercaya masyarakat Dayak Kayaan di Desa

Padua Mendalam sebagai hewan yang memiliki nilai ritual adat. Menurut hasil wawancara terhadap responden terpilih hewan tersebut hidup dihutan dan hingga saat ini hewan tersebut masih dimanfaatkan oleh masyarakat Dayak Kayaan. Tujuannya adalah agar masyarakat mendapatkan kehidupan yang baik dan hasil panen padi yang berlimpah.

\section{Kesimpulan}

Terdapat 9 jenis hewan dari 9 famili yang dimanfaatkan oleh masyarakat Suku Dayak Kayaan di Desa Padua Mendalam sebagai ritual adat sampai saat ini. Bagian yang dimanfaatkan terdiri dari seluruh tubuh, darah, kepala, bulu, ekor, dan cangkang. Seluruh tubuh merupakan bagian yang paling banyak dimanfaatkan oleh masyarakat Dayak Kayaan. Pemanfaatan hewan untuk ritual adat dipercaya dalam kehidupan masyarakat agar mereka mendapatkan kelancaran dalam melakukan kegiatan.

\section{Saran}

Saran yang dapat diusulkan berdasarkan dari hasil dan pembahasan artikel penelitian ini antara lain :
1. Salah satu upaya yang dapat dilakukan untuk melestarikan jenis-jenis hewan yang dilindungi adalah mengingatkan kembali nilai luhur yang dimiliki Suku Dayak Kayaan untuk memperkecil kemungkinan kepunahan hewan yang mereka manfaatkan.

2. Sedikitnya pengetahuan masyarakat Suku Dayak Kayaan di Desa Padua Mendalam Kecamatan Putussibau Utara Kabupaten Kapuas Hulu mengenai status perlindungan hewan sehingga perlu dilakukan sosisalisasi mengenai status konservasi kepada masyarakat.

\section{UCAPAN TERIMAKASIH}

Penulis mengucapkan terimakasih yang sebesar-besarnya kepada kedua orang tua, Agustinus Jaang (Alm) dan Vilomina Ipi yang telah memberikan dukungan, do'a dan material dalam menyelesaikan penyusunan artikel penelitian ini. Serta responden terpilih di Desa Padua Mendalam Kecamatan Putussibau Utara Kabupaten Kapuas Hulu yang telah meluangkan waktunya untuk memberikan informasi tentang pemanfaatan hewan sebagai ritual adat.

\section{DAFTAR PUSTAKA}

Agung. 1993. Kenangan Masa Lampau Zaman Kolonial Hindia Belanda Dan Zaman Pendudukan di Bali. Yayasan Obor Indonesia. Jakarta.

Eprilurahman R.I, Kusmana K, Yudha SD. 2012. Sekilas Etnozoologi Masyarakat Dayak Di Kalimantan. Fakultas Biologi Universitas Gadjah Mada.

Kartikasari, D., B.Masyud. \& M.D. Kusrini. 2008. Animal utilization as traditional medicine in Central 
Java. Proceedings of AZWMC Bogor.

Li, T.M. 1999. Transforming the Indonesian uplands marginalit, power and production. Singapore: Ed. Harwood Pantheon Books.

Noerwidi, S. 2010. Tembikar Muarakaman dalam Perspektif Kawasan. Balai Arkeologi Yogyakarta.

Putra, Y A E., B. Masy'ud., \& M. Ulfah. 2008. Keanekaragaman Satwa Berkhasiat Obat di Taman Nasional Betung Kerihun, Kalimantan Barat Indonesia. Media Konservasi, 13(1): 8-15.
Poerwandi EK. 1998. Pendekatan Kualitatif Dalam Penelitian Psikologi. Jakarta : Lembaga Pengembangan Sarana Pengukuran dan Pendidikan Psikologi (LPSP3) Fakultas Psikologi Universitas Indonesia. Jakarta.

Pilatus, Kartikawati SM, Anwari MS. 2017. Etnozoologi Suku Dayak Kanayant Di Desa Babane Kecamatan Samalantan Kabupaten Bengkayang. Fakultas Kehutanan Universitas Tanjungpura. Pontianak Vol.5 (3) : 858-867.

Suparlan P. 2005. Suku Bangsa Dan Hubungan Antar Suku Bangsa. Jakarta : Yayasan Pemgembangan Kajian Ilmu Kepolisian. 